\title{
RETRACTED ARTICLE: People Say There Are No Accidents: Poetry and Commentary
}

\author{
Caleb Gardner • Ladan Golestaneh • Baljean Dhillon • \\ Audrey Shafer
}

Published online: 14 January 2010

(C) Springer Science+Business Media, LLC 2010

\section{RETRACTED ARTICLE: J Med Humanit \\ DOI 10.1007/s10912-009-9096-2}

This article is a duplicate version of another article entitled "People Say There Are No Accidents: Poetry and Commentary" written by the same authors and published in Journal of Medical Humanities, Volume 31, Issue 3, pages 257-263, DOI: 10.1007/s10912-010-9113-5. Editor-in-Chief Therese Jones apologizes to the readers of the journal for not detecting this duplication during the publishing process. The online version of this article contains the full text of the retracted article as electronic supplementary material.

Electronic supplementary material The online version of this article (doi:10.1007/s10912-009-9096-2) contains supplementary material, which is available to authorized users.

C. Gardner

Studio 7 Arts, 7 Standish St., Cambridge, MA 02138, USA

e-mail: gardner.caleb@gmail.com

L. Golestaneh

Renal, Montefiore Medical Center, 111 East 210th St, Bronx,

NY 10467, USA

e-mail: lgolesta@montefiore.org

B. Dhillon

Ophthalmology, Royal Infirmary, University of Edinburgh,

Princess Alexandra Eye Pavilion, Edinburgh, UK

e-mail: bal.dhillon@luht.scot.nhs.uk

A. Shafer $(\bowtie)$

Anesthesia 112A, VAPAHCS, 3801 Miranda Ave, Palo Alto, CA 94304, USA

e-mail: ashafer@stanford.edu 